\title{
ESTUDOS DA QUALIDADE AMBIENTAL DO MONUMENTO NATURAL TRÊS MORRINHOS
}

\author{
Danilo de Oliveira1', Lucas César Frediani Sant' Ana² \\ ${ }^{1}$ Acadêmico do Curso de Geografia, Centro Universitário de Maringá - UNICESUMAR. Bolsista PIC/CNPq-Unicesumar. \\ danilo-oliveira83@hotmail.com \\ 2 Professor Doutor do colegiado de Geografia (EAD) - Unicesumar.campus Maringá \\ lucas.geografia@gmail.com
}

\section{RESUMO}

Historicamente, vivemos em um mundo cada vez mais globalizado, onde o bem natural é visto como um bem econômico, transformando a natureza em mero recurso. Assim, os redutos da natureza chamam a atenção daqueles que ainda se dispõe a perceber o valor da natureza ainda preservada. Por este motivo, propõe-se o estudo de caso no município de Terra Rica, noroeste do Estado do Paraná viabilizando pesquisa em uma das maiores áreas naturais desta região, nomeada de Morro Três Morrinhos. Localizado entre as longitudes 52 $40^{\prime}$ e 52 ${ }^{\circ} 37^{\prime}$ Oeste e latitude $22^{\circ} 46^{\prime}$ Sul, em uma altitude aproximada de 640 metros acima nível do mar, próximo à confluência dos Rios Paranapanema e Paraná. O monumento natural dos Três Morrinhos possui uma zona de abrangência de aproximadamente $25.000 \mathrm{~m} 2$ e a altura em torno de 200 metros (de sua base ao topo do maior morro). São formados geologicamente por arenitos silicificados da Formação Rio Paraná, do Grupo Caiuá, com uma estrutura geomorfológica destoante em sua região. Desta forma, a preservação, manutenção e utilização do ambiente natural prevê a produção em uma escala benéfica na conservação da natureza e sua utilização de maneira sustentável mantendo um potencial ao ponto de satisfazer as necessidades e aspirações das gerações futuras garantindo a sobrevivência dos seres vivos em geral.

PALAVRAS-CHAVE: Arenito Caiuá; Três Morrinhos; Unidade de Conservação.

\section{INTRODUÇÃO}

Historicamente, vivemos em um mundo cada vez mais globalizado, onde o bem natural é visto como um bem econômico, transformando a natureza em mero recurso. Assim, os redutos da natureza chamam a atenção daqueles que ainda se dispõe a perceber o valor da natureza ainda preservada. Assim, no município de Terra Rica, localizado no noroeste do Paraná encontra-se o monumento natural dos Três Morrinhos, que possui este nome justamente pela singularidade de sua paisagem, marcada pela presença de três morros justapostos. O modelado da superfície terrestre é o resultado da interação dos agentes exógenos e endógenos da Terra ao longo de milhões de anos, dando origem aos vales, cânions, montanhas, morros, etc. Para tanto, o objetivo maior do mencionando artigo é a efetivação no atendimento à Lei 9.985, de 18 de Julho 2000, que institui o Sistema Nacional de Unidades de Conservação - SNUC, no qual o município deve elaborar seu Plano de Manejo do Monumento Natural Três Morrinhos apresentando a documentação técnica que estabelece o zoneamento territorial e as normas que devem presidir o uso da Unidade de Conservação - UC, bem como de seus recursos naturais e a implantação de estruturas físicas necessárias à gestão da unidade.

A cidade de Terra Rica tem sua denominação de origem geográfica, dada pela própria companhia fundadora do município (SINOP - Sociedade Imobiliária do Noroeste do Paraná), que teve como objetivo exprimir a exuberância de suas terras férteis (FERREIRA, 2006). O relevo do município de Terra Rica varia de plano a moderadamente ondulado, entretanto, pode-se destacar o relevo do Morro Três Irmãos - ou apenas Três Morrinhos - que destoa completamente da geomorfologia da região noroeste do Paraná. O monumento natural batizado de Três Morrinhos tem por característica uma rica diversidade biológica e geográfica, tais como, paredões de rocha sedimentares, caverna, árvores centenárias, além disso, várias espécies de pássaros e animais, e o principal, um relevo singular na região noroeste do Paraná, despertando a curiosidade dos moradores e 
de turistas.

Os três morros perfilados no sentido NO-SE são um dos grandes atrativos turísticos da região noroeste do Paraná e também um dos melhores locais do sul do Brasil para a prática de voos livres, atraindo assim, pilotos de diversas partes do país nos campeonatos de paragliders e asa-delta (BRASIL, 2014). Possuidor de uma geomorfologia que ultrapassa milhões de anos, o Morro Três Irmãos é o ponto mais alto do Noroeste do Paraná, além é claro, de ser um atrativo turístico o espaço em questão surpreende pelos fatos, mitos e lendas relatados e preservados na história da própria terra.

Assim, sabe-se que toda a pesquisa requer métodos e instrumentos de seleção e medida para avaliar um problema, com o objetivo de dar inteligibilidade aos processos que diferenciam áreas, correlacionando unidades individuais a processos gerais a partir de indicadores que possibilitem similaridades e correlações (IBGE, 2006). Partindo dessa premissa, teremos como base o Sistema Nacional de Unidades de Conservação da Natureza - SNUC, que objetiva em seu Art. 4ํㅜ inciso VII proteger as características relevantes de natureza geológica, geomorfológica, espeleológica, arqueológica, paleontológica e cultural (BRASIL, 2000). Para Vargas (2016, p. 105) Monumento Natural, é a "área destinada à preservação de lugares singulares, raros e de grande beleza cênica, permitindo diversas atividades de visitação. Essa categoria de Unidade de Conservação pode ser constituída de áreas particulares".

\section{MATERIAIS E MÉTODOS}

O Morro Três Irmãos localizado no noroeste do Estado do Paraná, possui em sua área de abrangência 224.669 hectares na zona rural do município, 147.061 hectares em propriedades particulares e 77.608 hectares de áreas públicas, pertencentes ao Município. Seu acesso acontece pelas rodovias BR 376 e PR 180, ambas pavimentadas (LARANJA; KRAMER, 2009). De acordo com Calírio (2001), existem duas hipóteses sobre o surgimento do Morro Três Irmãos: a primeira delas apresenta-se como fenômenos geológicos ocorridos a milhões de anos, no qual se deu de forma retilínea. Todavia, supõe-se que o interior do Morro seja formado de basalto ou diabásio, ou seja, rocha magmática, recapeado por uma espessa camada de rocha sedimentar, o arenito do Grupo Caiuá. Já a segunda hipótese acredita-se que o local apresentou intensa silicificação deste arenito no qual resistiu nesses milhares de anos à atuação erosiva, sendo esta aceita atualmente no meio acadêmico.

Três Morrinhos são elevações anômalas, alongadas e solitárias [...] sua origem explica-se pela silicificação localizada de depósitos arenosos do antigo Deserto Caiuá, mediante ascensão de fluidos hidrotermais por sistemas de fissuras regionais, relacionada com magmatismo alcalino neocretáceo. $\mathrm{Na}$ evolução regional do relevo a erosão removeu de forma mais intensa os arenitos não silicificados. O topo dos Três Morrinhos deve corresponder, portanto, à cota mínima da superfície de aplainamento Sul-americana, elaborada entre Cretáceo Superior e Paleógeno (FERNANDES; COUTO; SANTOS, 2013, p. 1).

No entanto, apesar de o local ser transformado em Parque Municipal Três Morrinhos no ano de 2003 e receber um portal de entrada, como Centros de Educação Ambiental, em 2008, existem certas controversas no que tange ao monumento natural, levando-se em consideração que o espaço respectivamente não possui ao menos um Plano de Manejo. Para tanto, a Lei Federal n. $-9.985 / 00$ estabelece em seu Art. $2^{\circ}$, inciso $\mathrm{XVII}$, para os fins previstos entendendo-se que o Plano de Manejo é um:

Documento técnico mediante o qual, com fundamento nos objetivos gerais de uma unidade de conservação, se estabelece o seu zoneamento e as normas que 
devem presidir o uso da área e o manejo dos recursos naturais, inclusive a implantação das estruturas físicas necessárias à gestão da unidade (BRASIL, 2000, p.1).

Tendo em vista a importância da existência de um plano de manejo que norteie a gestão deste tipo de espaço, além dos levantamentos bibliográficos acerca do tema, serão realizadas visitas in situ com objetivo de identificar os principais problemas neste monumento natural, decorrente da ausência do plano de manejo.

\section{$3 \quad$ RESULTADOS E DISCUSSÕES}

Para esse estudo de caso a pesquisa contará com o levantamento da viabilidade no atendimento à Lei 9.985, de 18 de julho 2000, que institui o Sistema Nacional de Unidades de Conservação - SNUC, no qual o município deve elaborar seu Plano de Manejo. Entretanto, diante da discussão e informações levantadas pelos responsáveis pelo Morro, ao qual se apresenta como Parque Municipal Três Morrinhos não existe no momento um documento oficial para a defesa e preservação do Monumento Natural, alegando que o documento estaria sendo elaborado para os devidos fins legais e jurídicos de sua conservação.

Destarte, nota-se que o Morro Três Irmãos sofre frequentemente com queimadas, deixando um rastro de destruição e gerando risco aos visitantes daquela localidade. Esse tipo de impacto ambiental, por vezes, pode ser classificado como cultural, pois grande parte dos incêndios inicia-se com queimadas realizadas pelos agricultores, por vandalismos e até por bitucas de cigarro de fumantes que adentram a área. Logo, essa prática caracteriza-se como agressão contra a natureza, quando realizada sem controle ou de forma inadequada (CALÍRIO, 2001).

Nesse sentido, percebe-se o quão importante e necessário se torna o Plano de Manejo do Morro Três Irmãos, haja vista, as ocorrências de atitudes antrópicas modificando o reduto natural, onde o verde dá lugar às cinzas e os animais fogem de seu habitat natural.

\section{CONSIDERAÇÕES FINAIS}

Portanto, a elaboração de um Plano de Manejo que atenda as necessidades do Monumento Natural Morro Três Irmãos configurando-se no bojo da Lei 9.985, de 18 de Julho 2000, ao Sistema Nacional de Unidades de Conservação - SNUC demostra a urgência da valorização de nossas áreas naturais bem como a reinvindicação populacional perante aos representantes públicos pelo zelo para com nossas reservas.

Concomitantemente, assim, através dessa aplicabilidade poderemos preservar e cuidar de maneira positiva de nossas reservas, desta forma, incentivar a prática de um turismo sustentável nesta extensão tão rica em fauna e flora, como a manutenção e construção de trilhas para passeios e pesquisas ambientais e cientificas, considerando-se o potencial florestal, geológico e geomorfológico que os Três Morrinhos conservam em sua gênese.

\section{REFERÊNCIAS}

BRASIL. Lei no 9.985, de 18 de julho de 2000. Sistema Nacional de Unidades de Conservação da Natureza. Presidência da Republica Federativa do Brasil, Casa Civil, Subchefia para Assuntos Jurídicos, Brasilia, Distrito Federal. 18 de julho de 2000. Disponível em: <http://www.planalto.gov.br/ccivil_03/leis/l9985.htm>. Acesso em: 23 jul. 2019. 
BRASIL. Terra Rica, 59 anos de história: Morro Três Irmãos, um testemunho da história. Diário do Noroeste, 4 dez. 2014. Disponível em:

<http://www.diariodonoroeste.com.br/noticia/regiao/regional/63837-terra-rica--59-anos-dehistoria->. Acesso em: 28 jul. 2019.

CALÍRIO, Edson Paulo. Morro Três Irmãos: História, Lendas e Mistérios. Editora Gráfica Paranavaí Ltda, Paranavaí, 2001.

CALÍRIO, Edson Paulo. Vale do Paranapanema - Sonhos de uma Terra Rica, Editora Gráfica Paranavai Ltda, Paranavai, 2005.

FERNANDES, Luiz Alberto; COUTO, Edivando Vitor do; SANTOS, Leonardo José Cordeiro. Três Morrinhos, Terra Rica, PR: Arenitos silicificados de dunas do Deserto Caiuá testemunham nível de superfície de aplainamento K-T. Brasília: 2013. Disponível em: <http://sigep.cprm.gov.br/sitio058/sitio058.pdf>. Acesso em: 25 jul. 2019.

FERREIRA, João C. Vicente. Municipíos paranaenses - Origem e Significados de seus nomes, Cadernos Paraná da Gente n.5, Curitiba 2006.

IBGE, Manual técnico do uso da terra, 2006, 2 edição, Rio de Janeiro.

LARANJA, Nadir Gouveia; KRAMER, Vanda Maria Silva. SENSORIAMENTO REMOTO E GEOPROCESSAMENTO APLICADOS AOS ESTUDOS DE GEOMORFOLOGIA LOCAL (MORRO DOS TRÊS IRMÃOS ? TERRA RICA - PR). Paranavaí, 2009.

Disponível em:

<http://www.diaadiaeducacao.pr.gov.br/portals/cadernospde/pdebusca/producoes_pde/20 09_fafipa_geografia_artigo_nadir_gouveia_laranja.pdf>. Acesso em: 25 jul. 2019.

VARGAS, Karine Bueno. Recursos Naturais: Meio Ambiente e Desenvolvimento. Maringá-PR.: Unicesumar, 2016. 200 p. 